\title{
A project-based graduate level course in optical engineering
}

\section{Andrew Kirk}

Andrew G. Kirk, "A project-based graduate level course in optical engineering," Proc. SPIE 9663, Eighth International Topical Meeting on Education and Training in Optics and Photonics, 966325 (6 October 2003); doi: $10.1117 / 12.2208444$

SPIE Event: Eighth International Topical Meeting on Education and Training in Optics and Photonics, 2003, Tucson, Arizona, United States 


\title{
A project-based graduate level course in optical engineering
}

\author{
Andrew G. Kirk \\ Department of Electrical and Computer Engineering, McGill University \\ 3480 University St, Montreal, Quebec, H3A 2A7, CANADA \\ Tel.5143981542, Fax.514398 3127, email: andrew.kirk@mcgill.ca
}

\begin{abstract}
Here I describe the way in which a significant design and project component has been incorporated into a graduate level course on optical engineering in such a way as to be suitable for both novices in optics and also those with significant background. The course makes use of commercial optical ray tracing software.

(C)2003 Optical Society of America

OCIS codes: (000.2060) Education; (220.2740) Geometrical optics, optical design
\end{abstract}

\section{Background}

For several years I have been teaching a 500-level course entitled 'Optical Engineering' in the Department of Electrical and Computer Engineering at McGill. The enrollment in this course is typically $70 \%$ graduate students and 30\% senior undergraduates who have been accepted into the Honors Electrical Engineering program. Of the graduate students approximately one half are actually engaged in research in optics and photonics, whilst the remainder are studying a wide range of other subjects in electrical engineering. Some of the students arrive in class after having taken undergraduate optics courses which include significant coverage of geometrical optics, whilst others have seen very little optics since high school. This represents a challenge in trying to design a course that provides a solid foundation in free-space optics for those who have not previously studied it whilst also allowing more experienced students the opportunity to develop their knowledge further. In addition to providing a strong theoretical foundation in free-space optics I was also concerned to ensure that students were able to develop skills in optical design and developed familiarity with modern optical design software.

\section{Design Projects}

In order to achieve these objectives the course was restructured in order to include a significant design component. $\mathrm{CodeV} ®$ optical design software was introduced as a platform for teaching optical engineering. This was made possible by the educational research program of Optical Research Associates (the vendors of CodeV) which allowed the acquisition of short-term CodeV licenses. Students were allowed to install the software on their home computers and several copies were also made available within the department. The first half of the course was structured in such a way as to cover the essentials of optical design, including geometrical optics, aberrations and Gaussian beam optics. During this time students also wrote their own paraxial ray-tracing spreadsheets in order to understand better what the optical design software was doing. Tutorials in CodeV were offered and problems requiring the use of $\mathrm{CodeV}$ were assigned. At the start of the semester the students were also presented with a wide range of design projects, including imaging systems, sensors, disk pick-ups and components for optical telecommunications. They were required to work in pairs and to select one project to work on during the semester, with the objective of delivering a full optical design by the end of the semester. During the second half of the semester topics such as polarization, diffraction, interference and image evaluation were given.

\section{Outcomes}

This version of the course has now been given twice, to approximately 20 students in the first year of offering and 30 students in the second year. From an instructor's point of view the outcome has been very positive. Students demonstrated a much better knowledge of optics by doing the projects than they had previously with a more theoretical approach. Most of the students engaged very positively with the projects and delivered work of a very high standard. Figure 1 below is an example of the design of a MEMS-based retinal scanner contributed by two students. The project report of another pair was of such high quality that I decided to submit it to the Optical Research Associates CodeV annual design project where it was awarded first prize. The main challenge in this approach is to provide good tutorials in the use of $\mathrm{CodeV}$ and also to have sufficient teaching assistants who are 
experienced in $\mathrm{CodeV}$ and can troubleshoot when students arrive with questions and problems. More details on this approach, its benefits and limitations will be provided at the meeting.

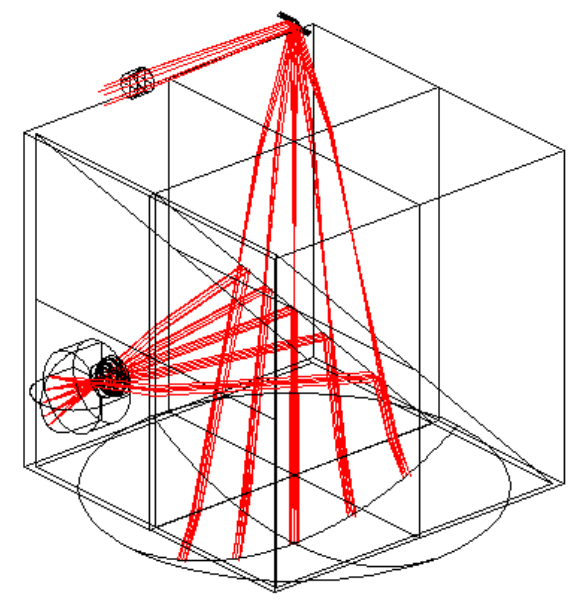

Fig. 1 Example of a design of a retinal scanner, submitted by E. Tremblay and C. Pulikkaseril 